\title{
Stage IIA Cervix
}

National Cancer Institute

\section{Source}

National Cancer Institute. Stage IIA Cervix. NCI Thesaurus. Code C96242.

A stage term referring to cervical cancer invading beyond uterus but not to pelvic wall or to lower third of vagina, without lymph node involvement or distant metastasis. There is no parametrial invasion. It includes: IIA1 (T2a1, N0, M0); IIA2 (T2a2, N0, M0). T2a1:

Clinically visible lesion $4.0 \mathrm{~cm}$ or less in greatest dimension. T2a2: Clinically visible lesion more than $4.0 \mathrm{~cm}$ in greatest dimension. N0: No regional lymph node metastasis. M0: No distant metastasis. (partially adapted from AJCC) 